\title{
SUBSURFACE VELOCITY MODEL FROM INVERSION OF H/V SPECTRAL RATIO OF AMBIENT NOISE RECORDS
}

\author{
Titi Anggono, a), Syuhada ${ }^{\text {b) }}$ \\ ${ }^{1}$ Research Center for Physics, Indonesian Institute of Sciences, Kawasan PUSPIPTEK Serpong, Tangerang \\ 15310 \\ Email: a)titi.anggono@lipi.go.id, b)syuhada@lipi.go.id
}

\begin{abstract}
The Horizontal-to-Vertical (H/V) spectral ratio method uses continuous ambient noise records has been used extensively to study the characteristics of site response due to the earthquake occurrence. Sources of ambient noise are usually from human activities or natural excitations and might be composed of body and surface wave components. Several studies have investigated the possibility to extract information on the shallow subsurface model from the inversion of $\mathrm{H} / \mathrm{V}$ spectral ratio. In this study, we investigated the shallow subsurface velocity model below two broadband seismometers at Simeulue Island, Aceh. Two broadband seismometers of PUTR and LEWK were selected because of the relatively clear peak amplitude of $\mathrm{H} / \mathrm{V}$ spectral ratios, which may reflect the existence of strong impedance contrast. The initial models are set to be fixed of five homogeneous medium layers with the last medium to be infinite homogeneous medium. By setting fixed layer boundaries in the inversion process, the velocities in the medium may vary to obtain the most suitable fitting to the observed $\mathrm{H} / \mathrm{V}$ spectral ratio. From the inversion process, we suggest we suggest that the strong impedance contrasts may occur on the shallow part of the medium at 2 up to $15 \mathrm{~m}$ depth.
\end{abstract}

Keywords: ambient noise records, H/V spectral ratio, inversion process.

\section{INTRODUCTION}

Site response, which is a response of a site to an incoming earthquake shaking, give important information on the site amplification factors. Several studies have used spectral ratio method to measure the S-wave part of the earthquake records to study the earthquake effect on the ground motion $[1,2]$. The spectral ratio method usually compares the observation results to reference rock sites response. The spectral ratio method, which uses earthquake data, needs long duration of seismometer installation high instrumental cost for obtaining good quality data. Nakamura introduced $\mathrm{H} / \mathrm{V}$ spectral ratio (HVSR) method, which measured the horizontal to vertical spectral ratio of ambient seismic noise records, to obtain information of the site response [3, 4]. The H/V spectral ratio method uses continuous ambient noise records. Sources of ambient noise are usually combinations from human activities or natural excitations and might be composed of body and surface wave components [5]. At low frequencies, typically less than $1 \mathrm{~Hz}$, the origin source of seismic noise is essentially natural with a particular emphasis on ocean waves. At higher frequencies, about larger than $1 \mathrm{~Hz}$, seismic noise sources may be associated with wind or water interaction. At much higher frequencies, the origin sources are dominantly due to human activities. The HVSR method have been frequently adopted in seismic microzonation studies [2, 6, 7, 8, 9]. The HVSR 
method is able to give information on the resonance or fundamental frequency of soil site with good impedance contrast $[10,11,12,13]$.

Malischewsky et al. in [14] carried out analytical studies to obtain the correlation between H/V spectral ratio and Rayleigh ellipticity assuming noise wavefield consists of Rayleigh waves [14]. They found that the frequency peak on the H/V spectral ratio curve corresponds to the shear wave resonance in the medium layer. Fäh et al. suggested that $\mathrm{H} / \mathrm{V}$ peak corresponds to a peak in the ellipticity and it is estimated to be between the peak frequency of resonance and the first minimum at higher frequency [15]. Several studies suggested that the shape of the H/V spectral ratio around its maximum peak can be used to determine $S$ wave velocity profile, such as shallow sites [16] or deep sedimentary basins $[17,18]$. We estimated impedance parameters from the observed H/V spectral ratio at two broadband seismometers at Simeulue Island, Sumatra.

Simeulue Island belongs to the outer island arc (Figure 1). The structures on the Island represent a collision complex between Indo-Australian and Eurasian plates. Faults trending NE-SW and NW-SE have been recognised on Simeulue Island. Block of faults are found along Pagaja fault in the northern region of the Island. Folds at the Island probably developed during Late Pliocene to Pleistocene period, which is during the uplift of the Island. Late Oligocene folds are developed within the Melange Complex, and have been reactivated since Late Miocene period [19].

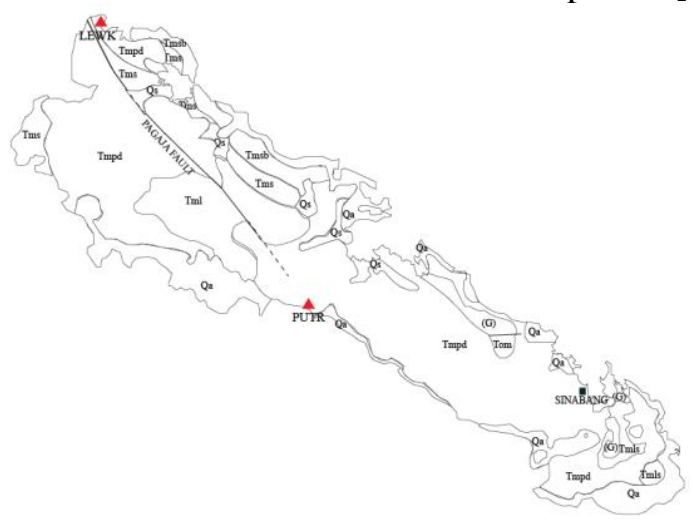

FIGURE 1. Map of Simulue Island, Aceh with the location of two broadband seismometers LEWK and PUTR. Each labels is geological outcrop of Simeulue Island. Tmls: Lasikin Member of Sigulai Formation; Tmsb: Sibigo Formations; Tms: Sigulai Formaiton; Tml: Layabaung Formation; Tmpd: Dihit Formation; Qa: alluvium; Qs: Swam Deposits; Qps: Reef Limestone; Tom (G): Kuala Makmur Melange [19].

TABEL 1. Station locations used in this study.

$\begin{array}{cccc}\text { Station } & \text { Latitude }(\mathbf{N}) & \text { Longitude }(\mathbf{E}) & \text { Data Time } \\ \text { PUTR } & 2.5809 & 96.0488 & 2005 / 12 / 1922.00 \\ \text { LEWK } & 2.9236 & 95.8041 & 2005 / 12 / 1922.00\end{array}$

\section{METHOD}

Two broadband seismometers PUTR and LEWK (Fig. 1) were part of a temporary seismic network installed at Simeulue Island in December 2005 - March 2006 [20]. The ambient noise record's period selected in this and the location of the seismometers are given in Table 1 . The H/V spectral ratio was process using Geopsy software (www.geopsy.org). We followed the procedure from SESAME (Site Effects Assessment using Ambient Excitations) document for processing the ambient seismic noise records [13]. We first removed instrument effect from the data records, and applied STA/LTA anti trigger algorithm to remove non stationary signal. STA (short term average) is the average level of signal amplitude over a short period of time, which we selected as $1.0 \mathrm{~s}$. LTA (long term average) is the average level of signal amplitude over a longer period of time, which we 
selected as $30.0 \mathrm{~s}$. Fourier amplitude spectra of each component was calculated with $25 \mathrm{~s}$ window length after applying 5\% cosine taper. We then averaged the two horizontal component amplitude spectra, calculated the $\mathrm{H} / \mathrm{V}$ spectral ratio for each window, and calculated the average $\mathrm{H} / \mathrm{V}$ spectral ratio. The H/V spectral ratio was computed in the $0.5-20 \mathrm{~Hz}$ range. Figure 2 shows an example of data processing of $\mathrm{H} / \mathrm{V}$ spectral ratio from one of the broadband seismometers. Raw seismogram data is shown in Figure 2(a), then we calculated the power spectral of vertical, NS and EW components as shown in Figure 2(b). We calculate the average of spectral component of horizontal components. We then calculated Horizontal-to-Vertical spectral ratio as shown in Figure 2(c).

We inferred subsurface model from the observed H/V spectral ratio. We used ModelHVSR, which based from the Monte Carlo inversion, to search the subsurface model by minimizing the misfit between the observed and theoretical $\mathrm{H} / \mathrm{V}$ spectral ratio [21]. In this program, the model is set to contain six parameters that are P-wave velocity (Vp), S-wave velocity (Vs), density, layer thickness, Q-factor of $\mathrm{P}(\mathrm{Qp})$ and $\mathrm{S}(\mathrm{Qs})$ waves. The amplification spectra is defined by three parameters, which are seismic impedance, travel time and quality factor. For simplicity, the layer thickness is chosen to be fixed as they are easier to measure in the field such as using borehole drilling, which are used as inversion constrain.

The processing step used in the ModelHVSR in this study can be described as following: the search is initiated with initial model whose parameters are randomly perturbed. The next perturbations are applied around the previous perturbations. In our inversion, we applied three stages of perturbations with 5,000 random tries or perturbations were carried out in each stage. In this procedure, the result from the previous perturbation stage was used to be the initial model for the following perturbation stage. In the inversion processing, depth for each layer was set to be fixed a and the last layer was set to be the infinite homogeneous model. Figure 3 shows the graphical user interface of ModelHVSR for PUTR data. Red, blue and black lines represent the observed H/V spectral ratio, initial H/V spectral ratio from the subsurface model and theoretical H/V spectral ratio from the inverted subsurface model, respectively.

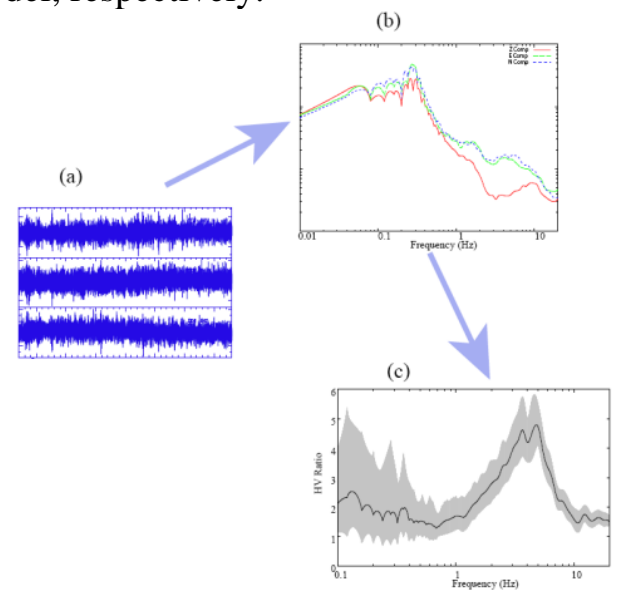

FIGURE 2. Example of $\mathrm{H} / \mathrm{V}$ spectral ratio processing. (a) Example of ambient seismic noise records from the seismogram. (b) Calculation of power spectral of the three components and (c) the calculation horizontal-to-vertical spectral ratio. 


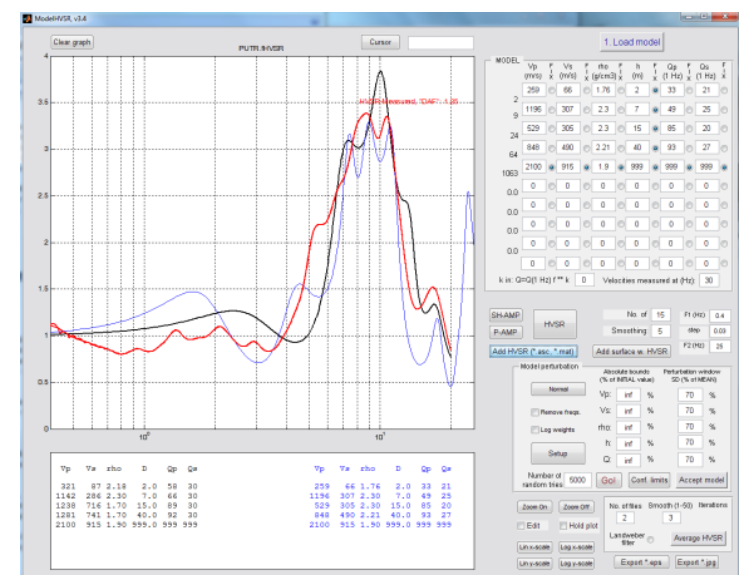

FIGURE 3. Graphical user interface from ModelHVSR using observed H/V spectral ratio from PUTR station.

\section{RESULTS AND DISCUSSION}

Theoretical and observed H/V spectral ratios for stations PUTR and LEWK are shown in Figure 4. The observed H/V spectral ratios for station PUTR and LEWK show amplitude is larger than 3 indicating a quite strong peak of $\mathrm{H} / \mathrm{V}$ spectral ratio. The observed strong peak of $\mathrm{H} / \mathrm{V}$ spectral ratio may indicate the occurrence of sharp impedance contrast beneath those sites [2]. The cause of strong peak of H/V spectral ratio may come due to the site sits on the top of the soft layer above a hard rock $[8,10]$. The impedance is a product of seismic velocity and density of layer medium.

Table 2 shows the obtained impedance parameters beneath each site from the inversion using ModelHVSR. We suggest sharp impedance contrast may occur at sites MAUD, LUAN, PUTR, LFAK and LEWK that reflects in the observed strong peak of $\mathrm{H} / \mathrm{V}$ spectral ratios [Figure 4]. Based on the inversion results, the strong impedance contrast occurs mostly at layer 1 up to layer 3 . Hence, we suggest that at Simeulue Island H/V spectral ratio mostly depends on the shallow part of the medium range between $2-15 \mathrm{~m}$ depth. The obtained substructure model then used to calculate theoretical $\mathrm{H} / \mathrm{V}$ spectral ratio. The theoretical H/V spectral ratio was calculated using ModelHVSR. We observed that the theoretical spectral ratios are reasonably well fit with the observed $\mathrm{H} / \mathrm{V}$ spectral ratios.
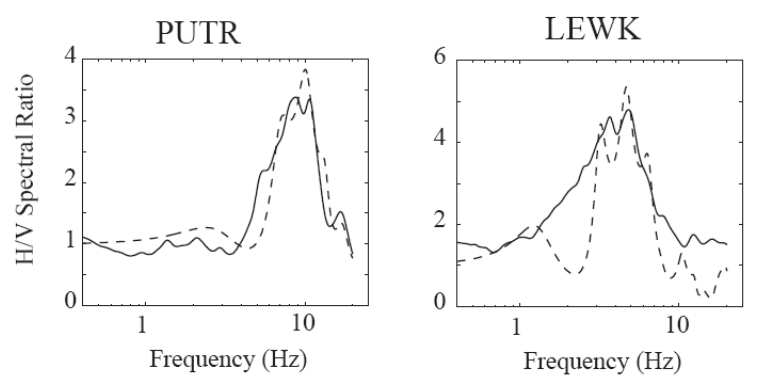

FIGURE 4. Theoretical and observed H/V spectral ratio at stations PUTR and LEWK. Solid and dashed lines represent observed and theoretical H/V spectral ratio, respectively.Figure 4.

As mentioned by Yamanaka et al. [27] there is a trade-off between layer thickness and shear wave velocity in the inversion process due to a nature of $\mathrm{H} / \mathrm{V}$ spectral ratio. It is necessary that the estimation of soil based on the H/V spectral ratio inversion need information of either soil thickness or shear wave velocity [22]. So that, in the inversion process, either thickness or shear wave velocity is searched; while, the other parameter is set at a fixed value. The information of soil thickness or 
shear wave velocity needs direct observation as a inversion constraint such as through borehole, which is not available in the sites at Simeulue Island. Due to the unavailability of these information, we cannot use a constraint to our inversion process using real data. In this study, we are able to show the possibility to infer the subsurface model from the observation of $\mathrm{H} / \mathrm{V}$ spectral ratio of ambient noise records.

\begin{tabular}{|c|c|c|c|c|c|c|}
\hline Layer & $\begin{array}{c}v_{p} \\
(\mathrm{~m} / \mathrm{s})\end{array}$ & $\begin{array}{c}v_{s} \\
(\mathrm{~m} / \mathrm{s})\end{array}$ & $\begin{array}{c}\rho \\
\left(\mathrm{kg} / \mathrm{m}^{3}\right)\end{array}$ & $\begin{array}{c}\boldsymbol{h} \\
(\mathbf{m})\end{array}$ & Qp & Qs \\
\hline \multicolumn{7}{|l|}{ Site PUTR } \\
\hline 1 & 321 & 87 & 2.18 & 2 & 58 & 30 \\
\hline 2 & 1142 & 286 & 2.30 & 7 & 66 & 30 \\
\hline 3 & 1238 & 716 & 1.70 & 15 & 89 & 30 \\
\hline 4 & 1281 & 741 & 1.70 & 40 & 92 & 30 \\
\hline 5 & 2100 & 915 & 1.90 & $\infty$ & $\infty$ & $\infty$ \\
\hline \multicolumn{7}{|l|}{ Site LEWK } \\
\hline 1 & 200 & 50 & 1.70 & 2 & 14 & 5 \\
\hline 2 & 495 & 124 & 2.04 & 7 & 64 & 25 \\
\hline 3 & 1295 & 343 & 2.30 & 15 & 72 & 30 \\
\hline 4 & 585 & 336 & 2.30 & 40 & 81 & 24 \\
\hline 5 & 2100 & 915 & 1.90 & $\infty$ & $\infty$ & $\infty$ \\
\hline
\end{tabular}

\section{CONCLUSION}

We have obtained information of the subsurface model beneath two broadband seismometer sites in Simeulue Island inferred from inversion $\mathrm{H} / \mathrm{V}$ spectral ratio of ambient seismic noise. However, in this study we do not have information of real velocity or layer depth that can be used as a constraint in the inversion process. To have more realistic model, it is necessary to have information on the subsurface velocity or layer thickness obtained from borehole measurements.

\section{ACKNOWLEDGEMENTS}

The broadband seismometers were provided by SeisUK (loan 800). Data are available through the IRIS Data Management Center. IRIS Data Services are funded through the Seismological Facilities for the Advancement of Geoscience and EarthScope (SAGE) Proposal of the National Science Foundation under Cooperative Agreement EAR-1261681. Some Figures were prepared using the Generic Mapping Tools (GMT) by Wessel and Smith (1991).

\section{REFERENCES}

[1] Akinci, A., Malagnini, L. and Sabetta, F., Characteristics of the strong ground motions from the 6 April 2009 L'Aquila earthquake, Italy, Soil Dynamics and Earthquake Engineering, 30(5) (2010), p. 320-335.

[2] Haghshenas, E., Bard, P.-Y. and Theodulidis, N., Empirical evaluation of microtremor H/V spectral ratio, Bulletin of Earthquake Engineering, 6(1) (2008), p. 75-108.

[3] Nakamura, Y., A Method for Dynamic Characteristics Estimation of Subsurface using Microtremor on the Ground Surface, Quarterly Report of Railway Technical Research Institute, 30(1) (1989), p. 25 - 33.

[4] Nakamura, Y., Clear identification of fundamental idea of Nakamura's technique and its applications, Proceeding of the 12th Word Conference on Earthquake Engineering (2000), 2656. 
[5] Bonnefoy-Claudet, S., Cornou, C., Bard, P.-Y., Cotton, F., Moczo, P., Kristek, J. and Fah, D., H/V ratio: a tool for site effects evaluation. Results from 1-D noise simulations, Geophysical Journal International, 167(2) (2006), p. 827-837.

[6] Macau, A., Figueras, S., Roulle, A., Kingne, L., Bellmunt, F. and Meneses, C., Seismic Microzonation in two Pyrenean Valleys: Val d'Aran and Luchonnais, Proceeding of the 15th Word Conference on Earthquake Engineering (2012), 4145.

[7] Flores, H., Malischewsky, P. and Jentzsch, G., H/V spectral ratio analysis and Rayleigh modelization in Eastern Thuringia, Germany, Geofisica Internacional, 52(4) (2013), p. 355364.

[8] Vella, A., Galea, P. and D'Amico, S., Site frequency response characterisation of the Maltese islands based on ambient noise H/V ratios, Engineering Geology, 163 (2013), p. 89100.

[9] Liu, L., Chen, Q., Wang, W. and Rohrbach, E., Ambient noise as the new source for urban engineering seismology and earthquake engineering: a case study from Beijing metropolitan area, Earthquake Science, 27(1) (2014), p. 89-100.

[10] Duval, A.M., Bard, P.-Y., Lebrun, B., Lacave-Lachet, C., Reipl, J. and Hazfeld, D., H/V technique for site response analysis: synthesis of data from various surveys, Bollettino di Geofisica Teorica ed Applicata, 42 (2001), p. 267-280.

[11] Priolo, E., Michelini, A., Laurenzano, G., Addia, R. and Puglia, A., Seismic response from microtremors in Catania (Sicily, Italy), Bollettino di Geofisica Teorica ed Applicata, 42 (2001), p. 335-359.

[12] Horike, M., Zhao, B. and Kawase, H., Comparison of site response characteristics inferred from microtremors and earthquake shear waves, Bulletin Seismological Society of America, 91 (2001), p. 1526-1536.

[13] Bard, P.-Y. et al., Guidelines for the implementation of the $H / V$ spectral ratio technique on ambient vibrations. Measurements, processing and interpretation. SESAME European Research Project WP 12 - Deliverable D23.12, European Commission., 2004.

[14] Malischewsky, P.G. and Scherbaum, F., Love's formula and H/V-ratio (ellipticity) of Rayleigh waves, Wave Motion, 40 (2004), p. 57 - 67.

[15] Fäh, D., Kind, F. and Giardini, D., Inversion of local S-wave velocity structures from average $\mathrm{H} / \mathrm{V}$ ratios, and their use for the estimation of site-effects, Journal of Seismology, 7(4) (2003), p. $449-467$.

[16] Fäh, D., Kind, F. and Giardini, D., A theoretical investigation of average H/V ratios, Geophysical Journal International, 145 (2001), p. 535 - 549.

[17] Yamanaka, H., Takemura, M., Ishida, H. and Niea, M., Characteristics of long-period microtremors and their applicability in exploration of deep layers, Bulletin of Seismological Society of America, 84 (1994), p. 1831 - 1841.

[18] Satoh, T., Kawase, H. and Matsushima, S., Differences between site characteristics obtained from microtremors, S-waves, P-waves and codas, Bulletin Seismological Society of America, 91 (2001), p. 313 - 334.

[19] Endharto, M. and Sukido, Geological map of the Sinabang Quadrangle, Sumatra, Quadrangle 0518, Scale 1:250,000, Geological Research and Development Centre, Bandung, Indonesia, 1994.

[20] Tilmann, F. J., Craig, T. J., Grevemeyer, I., Suwargadi, B., Kopp, H. and Flueh, E., The updip seismic/aseismic transition of the Sumatra megathrust illuminated by aftershocks of 
the 2004 Aceh-Andaman and 2005 Nias events, Geophysical Journal International, 181(3) (2010), p. 1261-1274.

[21] Herak, M., ModelHVSR - A Matlab tool to model horizontal-to-vertical spectral ratio of ambient noise, Computers \& Geosciences, 34(11) (2008), p. 1514 - 1526.

[22] Arai, H. and K. Tokimatsu, S-wave velocity profiling by inversion of microtremor H/V spectrum, Bulletin of the Seismological Society of America, 94(1) (2004), p.53-63. 
Spektra: Jurnal Fisika dan Aplikasinya http://doi.org/10.21009/SPEKTRA
Volume 2 Nomor 1 , April 2017
p-ISSN: 2541-3384

e-ISSN: 2541-3392 